\title{
Verdades em (des)construção: uma análise sobre as práticas integrativas e complementares em saúde
}

\section{(De)construction of truths: an analysis about integrative and complementary practices in health}

\section{Roberta de Pinho Silveira ${ }^{a}$}

(iD) https://orcid.org/0000-0003-4136-9253

E-mail: robertapinho20ı6œgmail.com

\section{Cristianne Maria Famer Rochab}

(D) http://orcid.org/0000-0003-3281-2911

E-mail: cristianne.rocha®ufrgs.br

aPesquisadora autônoma do Grupo de Estudos de Promoção da Saúde (GEPS) na Escola de Enfermagem da Universidade Federal do Rio Grande do Sul, Porto Alegre, RS, Brasil.

buniversidade Federal do Rio Grande do Sul. Escola de Enfermagem. Departamento de Saúde Coletiva. Porto Alegre, RS, Brasil.

\section{Correspondência}

Roberta de Pinho Silveira

Rua São Manoel, 963, Rio Branco. Porto Alegre, RS, Brasil.

CEP 90040-060.

\section{Resumo}

Neste artigo, buscamos conhecer como foram se constituindo alguns dos regimes de verdade sobre as práticas integrativas e complementares em saúde (Pics) nas políticas públicas de saúde, especialmente na Política Nacional de Práticas Integrativas e Complementares (PNPIC), com a inclusão de saberes e práticas não convencionais no Sistema Único de Saúde (SUS). Por meio de uma abordagem qualitativa inspirada no método genealógico de Michel Foucault, as Pics são analisadas como uma invenção, uma fabricação que teve sua emergência na PNPIC. Dessa forma, este estudo possibilita refletir sobre alguns dos regimes de verdade que constituem as Pics, em suas convergências com os discursos e as práticas da promoção da saúde, na vertente que responsabiliza os estilos de vida nos processos de saúde e doença. Ao mesmo tempo, tais discursos, por meio do dispositivo do risco, direcionam as condutas dos indivíduos e da população, produzindo corpos e subjetividades controlados pelas políticas neoliberais.

Palavras-chave: Práticas Integrativas e Complementares em Saúde; Promoção da Saúde; Genealogia; Michel Foucault. 


\section{Abstract}

The objective of this article is to analyze the formation of a system of truths concerning the public policies for integrative and complementary practices in health care (PICS), especially in the National Policy for Integrative and Complementary Practices (PNPIC), which included nonconventional knowledge and practices in the Brazilian National Health System (SUS). We thus analyze the PICS as an invention that emerged from the PNPIC, in a qualitative investigation inspired by Michel Foucault's genealogy. This study enables the reflection on the system of truths that constitute the PICS, converging in discourses and practices of health promotion that places the responsibility of the health and disease processes on the lifestyles of individuals. Concurrently, this very discourse drives individual and collective attitudes using the device of risk, producing bodies and subjectivities controlled by neoliberal policies.

Keywords: Integrative and Complementary Practices in Health; Health Promotion; Genealogy; Michel Foucault.

\section{Sobre as práticas integrativas $e$ complementares em saúde}

A Política Nacional de Práticas Integrativas e Complementares (PNPIC) foi implementada no Brasil por meio da Portaria do Ministério da Saúde no 971 (Brasil, 2006a), que incluiu no Sistema Único de Saúde (SUS) saberes e práticas não convencionais de saúde. Inicialmente, eram apenas cinco: homeopatia, medicina tradicional chinesa/acupuntura, fitoterapia, medicina antroposófica e termalismo/crenoterapia. A escolha de apenas algumas práticas integrativas e complementares em saúde (Pics), entre tantas outras, pode ser explicada, de acordo com Moebus e Merhy (2017), pelo fato de que seus praticantes contavam com maior estrutura e representatividade para legitimar, por meio da PNPIC, práticas de saúde que já vinham sendo utilizadas na atenção à saúde da população. Em março de 2017, mais 14 práticas foram incluídas na PNPIC, sendo elas: arteterapia, ayurveda, biodança, dança circular, ioga, meditação, musicoterapia, naturopatia, osteopatia, quiropraxia, reflexoterapia, reiki, shantala e terapia comunitária. Mais recentemente, também passaram a fazer parte da PNPIC as seguintes modalidades: apiterapia, aromaterapia, bioenergética, constelação familiar, cromoterapia, geoterapia, hipnoterapia, imposição de mãos, ozonioterapia e terapia de florais (Brasil, 2018).

Entre as 29 modalidades de Pics, podemos encontrar uma pluralidade de saberes e práticas de saúde. Para Queiroz (2006), a homeopatia, a acupuntura e a medicina antroposófica, assim como outras racionalidades e práticas não convencionais de saúde, partilhariam uma perspectiva vitalista que se caracteriza por uma visão holística e integradora ao perceber a energia como constituidora e organizadora da matéria. Nesse sentido, colocam questionamentos importantes quanto ao "reducionismo biológico, o mecanicismo, a ênfase na estatística, o primado do método sobre o fenômeno e da doença sobre o doente" (Queiroz, 2006, p. 19). Além de práticas que relacionamos objetivamente com cuidados em saúde, a PNPIC oferece também práticas que poderíamos relacionar ao lazer ou à cultura, como a musicoterapia, a arteterapia, as danças circulares, entre outras. Nesse sentido, as mais diversas atividades da vida social, 
como os hábitos esportivos, as práticas artísticas e as religiosas, passam a ser consideradas práticas de saúde (Furtado; Szapiro, 2012).

As Pics ganharam visibilidade, para que fossem instituídas como política pública de saúde no Brasil, por influência da Organização Mundial de Saúde (OMS), que as classifica como medicinas tradicionais e complementares, resultado de uma fusão entre as medicinas tradicionais e as medicinas alternativas e complementares, que envolvem produtos, práticas e profissionais (OMS, 2013). A medicina alternativa e complementar refere-se ao amplo conjunto de práticas de atenção à saúde que não são parte da tradição ou da medicina convencional, assim como não estão totalmente integradas ao sistema de saúde predominante de um dado país. Em alguns locais, esses termos são utilizados indistintamente para referir-se à medicina tradicional, que se constitui de histórias milenares cujos conhecimentos, capacidades e práticas são baseados em teorias, crenças e experiências próprias de diferentes culturas, utilizadas para manter a saúde, prevenir, diagnosticar, melhorar ou tratar enfermidades físicas e mentais (OMS, 2002).

Para Martins (2012), as medicinas alternativas seriam outras medicinas, compostas por um conjunto de saberes, práticas e tecnologias de variadas origens históricas e geográficas, cujo crescimento e aceitação ocorre no mundo todo, apesar de o discurso biomédico apontar uma carência de legitimidade científica nessas práticas. Contudo, o autor observa que, o mesmo discurso biomédico desconsidera essa insuficiência de racionalidade caso a funcionalidade técnica de alguma medicina alternativa seja aplicada por um profissional médico.

A questão epistemológica sobre as racionalidades dos saberes e das práticas de saúde foi analisada por Luz (2012), que considera como racionalidade médica os sistemas médicos complexos constituídos por seis dimensões: (1) uma cosmologia, que seria a própria tessitura cultural de onde podem derivar as outras dimensões; (2) uma morfologia, que descreve o corpo humano; (3) uma dinâmica vital, que explica os equilíbrios e desequilíbrios do corpo humano e suas causas; (4) uma doutrina médica, que apresenta um repertório das causas, efeitos e definições do adoecer; (5) um sistema de diagnose, que determina as características dos processos mórbidos do corpo; e, por fim, (6) um sistema terapêutico que ofereça formas de intervenção sobre a doença. Desse modo, foi possível afirmar que a biomedicina não seria a única medicina portadora de racionalidade. Ao contrário, esse conceito indicou existirem outras três racionalidades médicas: a medicina ayurvédica, a medicina tradicional chinesa e a medicina homeopática.

Para os profissionais da enfermagem, conforme Schveitzer e Zoboli (2014, p. 193), as Pics costumam ser relacionadas à "valorização das tecnologias leves”, que são os modos de cuidado realizados no momento mesmo do trabalho, em que o próprio encontro terapêutico, baseado em práticas de saúde menos tecnológicas e mais relacionais, é o que se considera importante para o cuidado em saúde (Merhy; Feuerwerker, 2009). Por outro lado, é possível observar que muitos profissionais de saúde, em seus discursos sobre as Pics, evocam ideias mais afinadas com uma atenção à saúde convergente com o modelo biomédico da prevenção, referindo-se aos benefícios para a saúde proporcionados por essas práticas por meio de termos como "evitar", "prevenir" ou “informar” (Lima; Silva; Tesser, 2014, p. 266). Segundo Martins (2012), em alguns momentos os discursos biomédicos desqualificam as Pics e, em outros, se dedicam a capturar seus sentidos por meio da produção de discursos que caracterizem tais práticas conforme os moldes do paradigma biomédico. Nesse sentido, de acordo com Perurena (2014), o maior impeditivo para o fortalecimento das Pics no SUS se deve ao poder hegemônico do modelo biomédico na definição das possibilidades de atenção à saúde da população.

Tamanha variação numa mesma política suscita curiosidade. Afinal, qual seria a convergência ou o que justificaria a reunião de práticas tão heterogêneas num mesmo grupo, formando uma unidade como a colocada pela invenção das Pics? Impulsionadas por essa pergunta, buscamos, neste artigo, analisar como as Pics - enquanto uma invenção que teve sua emergência na PNPIC - foram constituindo alguns dos regimes de verdade sobre os saberes e as práticas não convencionais em saúde. 
Sobre um modo de analisar: influências da pesquisa genealógica

Existem diversas possibilidades para narrar uma história, seja de uma vida, de um saber ou mesmo da implementação de uma política pública de saúde. São as histórias sobre como as coisas chegam a ser o que são, por meio dos discursos e das práticas empreendidas, que nos contam as condições que tornam algo possível. Ao conhecer variados discursos e práticas que se relacionam a alguma coisa, podemos desnaturalizar os objetos, os conceitos e as verdades relacionados aos temas das nossas pesquisas. Assim, os saberes e as práticas em saúde podem ser analisados à luz da atualidade, observando-se sua construção histórica. Portanto é necessário considerar que as histórias, ao se estabelecerem como uma verdade, são mais precisamente o resultado de diferentes disputas empreendidas por variados grupos sociais num tempo e lugar, de forma que não constituem a única história sobre um tema (Baptista; Mattos, 2015).

Nesse sentido, segundo Rago (2015, p. 257), “é preciso deslegitimar o presente, desfazendo os fios da continuidade histórica, que sustentam as noções de identidade", para que a releitura do passado possa mostrar outras histórias. Assim sendo, as verdades que se estabelecem nos nossos discursos sobre a saúde não devem ser tomadas como absolutas ou imutáveis porque são contingentes e estabelecidas por meio de disputas interessadas e políticas.

Para analisar um objeto que reúne saberes e práticas de alguma forma realizadas no SUS, mas que não podem ser consideradas biomédicas e, portanto, formam uma unidade composta pelo não convencional, nos inspiramos no método genealógico de Michel Foucault para problematizar alguns dos regimes de verdade sobre as Pics. A genealogia é uma pesquisa paciente e documentária, que busca perceber os pequenos jogos de verdade das histórias que se estabelecem como fiéis retratos da verdade. Para tal, é preciso olhar cuidadosamente as minúcias, os detalhes que parecem não ter importância. A genealogia é cinza, não haverá nada que salte aos olhos num colorido destaque. É preciso olhar sem pressa e demoradamente porque o que há por trás das coisas é uma construção histórica que resulta de disputas, de relações de poder e, por consequência, do estabelecimento de verdades.

Apesquisa genealógica possibilita compreender o campo das práticas sociais e como elas corroboraram a invenção de determinados objetos, verdades e práticas. Nesse sentido, a genealogia trata, segundo Foucault (2006, p. 171), da insurreição dos saberes locais "contra os efeitos de poder centralizadores que estão ligados à instituição e ao funcionamento de um discurso científico organizado no interior de uma sociedade como a nossa”. Tal investigação opera um deslocamento: o saber passa a ser analisado por sua natureza política. Assim, conforme Foucault (2006, p. 172), a genealogia torna possível "libertar da sujeição os saberes históricos, isto é, torná-los capazes de oposição e de luta contra a coerção de um discurso teórico, unitário, formal e científico". Portanto a genealogia procura tornar saberes e práticas não hegemônicos capazes de resistir a silenciamentos, desqualificações e coerções, assim como pode tornar visível a modulação que os mecanismos das biopolíticas produzem nos discursos concebidos acerca de saberes e práticas de saúde não biomédicos.

O conceito de biopolítica foi introduzido por Foucault, em 1974, ao relacioná-lo com o nascimento da medicina social (Caponi, 2014). Ali, o autor demonstrou que a medicina moderna representou uma prática social que se utilizava de certa tecnologia do corpo social, fundamental para o desenvolvimento do capitalismo em fins do século XVIII e no início do século XIX (Foucault, 2006). Assim, o poder disciplinar foi uma estratégia para individualizar e tornar os corpos fortes e capacitados para multiplicar o trabalho, ao mesmo tempo que os enfraquecia politicamente. Por sua vez, a biopolítica não substituiu o poder disciplinar, mas integrou a este a capacidade de dirigir-se à população e a seus processos biológicos e biossociológicos, configurando uma estratégia de poder massificadora que se refere ao homem como espécie humana (Caponi, 2014).

Portanto podemos usar o conceito de biopolítica como um instrumento eficaz para olhar para os processos de gestão das populações a fim de perceber como estes, ao mesmo tempo que perpetuam desigualdades, são também orientados pela noção de 
risco à saúde. Assim, a partir de um conjunto de dados sobre a população, como as taxas de mortalidade, de suicídio, de alcoolismo ou da loucura, entre outros controles, se instaura uma lógica securitária. Esta se apresenta como antecipadora dos riscos que podem nos alcançar, e esse dispositivo risco-segurança estabelece as garantias para que se constitua uma legitimidade e uma aceitabilidade da população quanto a essa estratégia de poder massificadora (Caponi, 2014).

\section{Regimes de verdade das práticas integrativas e complementares em saúde}

Para analisar como as Pics foram constituindo alguns dos regimes de verdade sobre saberes e práticas não convencionais em saúde, procuramos desnaturalizar o objeto do nosso estudo ao buscar conhecer quais foram as condições de possibilidade para sua emergência na PNPIC. Dessa forma, observamos os jogos de verdade que podem nos mostrar as estratégias sociais, econômicas e culturais usadas nas disputas para estabelecer ou manter regimes de verdade (Foucault, 2006).

Nas sociedades influenciadas pela razão moderna, existe uma economia política da verdade, que tem características históricas importantes, conforme analisada por Foucault (2006, p. 13):

A "verdade" é centrada na forma do discurso científico e nas instituições que o produzem; está submetida a uma constante incitação econômica e política (necessidade de verdade tanto para a produção econômica, quanto para o poder político); é objeto, de várias formas, de uma imensa difusão e de um imenso consumo (circula nos aparelhos de educação ou de informação, cuja extensão no corpo social é relativamente grande, não obstante algumas limitações rigorosas); é produzida e transmitida sob o controle, não exclusivo, mas dominante, de alguns grandes aparelhos políticos ou econômicos (universidade, exército, escritura, meios de comunicação).

Nesse sentido, segundo Foucault (2006), os regimes de verdade delimitam quais discursos serão acolhidos e irão funcionar como verdades. Isso ocorre através de vínculos com um "regime político, econômico e institucional de produção de verdade" (Foucault, 2006, p. 14). Por consequência, a história não pode ser tomada como numa narrativa metafísica de contínuo e inequívoco progresso de uma tendência original ou essencial. Para Foucault (2013), a ideia de um começo de todas as coisas, onde encontraríamos uma essência em estado de perfeita criação, é risível e ilusória. Ao contrário, o que encontramos no começo de todas as coisas são disputas, interesses e lutas.

O conhecimento é produzido por mecanismos ou realidades diversas, num embate em que o conhecimento ocorre por meio da violência, da dominação ou da violação das coisas a se conhecer. A verdade é produzida, fabricada, inventada e posta em circulação segundo relações estratégicas, relações de poder em que há posições tomadas, em que o homem se encontra situado e, portanto, adere a alguma perspectiva (Foucault, 2013).

\section{Promoção da saúde e o governo das condutas}

Ao analisarmos o que é dito sobre as Pics, questionamos quais são os regimes de verdade que constituem seus discursos. Então retomamos o momento inaugural da PNPIC, em 2006, cuja implementação ocorreu, entre outros motivos, como uma resposta à necessidade de garantir a produção da integralidade na atenção à saúde, considerando também a necessidade de "conhecer, apoiar, incorporar e implementar experiências" (Brasil, 2oo6b, p. 4) que já aconteciam nos serviços públicos de saúde dos municípios e estados, mas eram desprovidas de normatização ou regulamentações. Essa presença heterogênea e desregrada das práticas de saúde não convencionais foi tratada, por meio dos discursos formulados na PNPIC, como uma insuficiência de segurança, eficácia e qualidade na sua realização. Apesar de se apresentar como uma política para ser exercida "na perspectiva da integralidade do cuidado da atenção à saúde” (Brasil, 2oo6b, p. 5), a PNPIC não dispensou a normatização e a regulamentação das Pics no processo de legitimação destas no sistema público de saúde. 
Dessa forma, a integralidade, como descrita na PNPIC, se aplica como perspectiva para a normalização de saberes e práticas não biomédicos em saúde e parece não superar o modelo da racionalidade moderna ocidental e da evidência científica como critério de segurança. De acordo com Pinheiro (2006), a integralidade é um dos princípios doutrinários do SUS, podendo ser pensada como um modo de produzir uma prática de cuidado que não ofereça apenas respostas delimitadas pela concepção biológica da saúde e que incorpore técnicas de prevenção para diminuir o consumo de bens e serviços de saúde; propõe um cuidado não fragmentado e, portanto, com articulações horizontais entre as práticas de saúde por meio da aplicação de protocolos para diagnóstico e identificação dos riscos à saúde.

Se, por um lado, é difícil imaginar que os saberes e as práticas plurais que compõemas Pics possam sobreviver a protocolos atentos aos riscos em saúde, por outro lado, podemos pensar nas Pics como saberes e práticas que incentivam a realização da integralidade no SUS ao promover experiências de cuidado em saúde orientadas por saberes e práticas variados, que ampliam os sentidos do cuidado em saúde de forma a não restringir as ações às práticas curativas. No entanto, a ideia de uma visão ampliada da saúde está relacionada ao ideário da promoção da saúde, que podemos ver bem representada na definição da PNPIC sobre as Pics:

Tais sistemas e recursos envolvem abordagens que buscam estimular os mecanismos naturais de prevenção de agravos e recuperação da saúde por meio de tecnologias eficazes e seguras, com ênfase na escuta acolhedora, no desenvolvimento do vínculo terapêutico e na integração do ser humano com o meio ambiente e a sociedade. Outros pontos compartilhados pelas diversas abordagens abrangidas nesse campo são a visão ampliada do processo saúde-doença e a promoção global do cuidado humano, especialmente do autocuidado. (Brasil, 20o6b, p. 10)

Essa citação da PNPIC expressa alguns regimes de verdade. Ao se referir às tecnologias eficazes e seguras, por exemplo, o texto nos subjetiva com a ideia de que a biomedicina, cujo método se baseia em evidências científicas, seria a única prática de saúde verdadeira, segura e infalível. Além disso, o discurso da política sugere que a influência normativa, regulamentadora e ordenadora poderia colaborar para garantir eficácia e segurança no uso das Pics. No entanto, cabe aqui indagar se essas seriam preocupações colocadas em questão no interior dos saberes e das práticas não convencionais. Ainda, na sequência dessa mesma citação, há referência à visão ampliada do processo saúde-doença e ao autocuidado, noções que aparecem articulando práticas e discursos convergentes para o conceito de promoção da saúde, na vertente que responsabiliza os estilos de vida nos processos de saúde e doença. Em consequência, coloca-se em circulação um regime de verdades que tem empreendido o governo das condutas, produzindo corpos e subjetividades e, portanto, modos de vida. Com a ampliação da saúde, todas as dimensões da vida podem ser medicalizadas. Nesse sentido, as Pics funcionam como tecnologias para que os sujeitos possam aderir aos regimes deverdade postos no campo da saúde, de modo a gerenciar suas vidas com o objetivo de evitar os riscos que podem fazê-los adoecer. Assim, o discurso sanitário do autocuidado é um importante regime de verdade na sociedade em que vivemos.

A medicalização seria “o excesso de intervencionismo médico sobre os corpos e vida das pessoas e está relacionada ao abuso do poder médico e, também, à expansão do consumo de bens e serviços de saúde de interesse para o mercado" (Costa, 2004, p.13), produzindo, segundo Gaudenzi e Ortega (2012), uma apropriação da vida das pessoas pela biomedicina. Assim, a medicalização se relaciona à incorporação de normas de conduta de origem biomédica, processo no qual as experiências humanas passam a ser consideradas problemas médicos.

Ao analisar os sentidos possíveis da medicalização, Zorzanelli, Ortega e Bezerra Júnior (2014) observam que esta é um dispositivo central no exercício da biopolítica, efetivando-se na patologização de aspectos relativos a questões da vida e dos corpos (como a infância e a sexualidade), que pode ser destacada na obra de Foucault em, no mínimo, dois sentidos - indissociáveis e, no entanto, com cronologias diferentes: o primeiro é localizado na 
formação dos Estados modernos, que se constituíram por meio da normalização dos corpos, dos espaços, das cidades e das populaçõe; enquanto o segundo, derivação do primeiro, mas localizado no período pós-Segunda Guerra, diz respeito “à impossibilidade de descrever experiências com o corpo humano que não passem, em algum sentido, pelo saber médico" (Zorzanelli; Ortega; Bezerra Júnior, 2014, p. 1861).

A ideia de uma ampliação do conceito de saúde é antiga: podemos encontrá-la relacionada à moderna promoção da saúde que, de acordo com Buss (2000), entrou em discussão com o documento $A$ new perspective on the health of Canadians, de 1974, que ficou conhecido como Informe Lalonde e teve como motivação a necessidade de enfrentar o dispendioso e crescente custo da assistência médica, que se somava à constatação de seus resultados pouco significativos em relação ao tratamento de doenças crônicas. Esse documento utilizou a concepção de "campo da saúde”, caracterizado por quatro grupos que determinam o processo saúde-doença: a biologia humana, a organização dos serviços de saúde, o estilo de vida e o ambiente natural e social. A ênfase dada ao estilo de vida foi posteriormente apontada como responsável pela culpabilização da vítima, afinal, para extratos da população à margem do desenvolvimento capitalista, existe a impossibilidade de manter estilos de vida livres dos riscos à saúde (Carvalho, 2004).

Como costuma acontecer nos jogos de verdade, o Informe Lalonde, ao promover discursos sobre o conceito de promoção da saúde, articulou uma pauta discursiva para o campo da saúde. Dessa forma, em Alma-Ata (Cazaquistão), além da proposta de elencar a atenção primária como eixo estruturante dos sistemas nacionais de saúde, a OMS coloca os seguintes discursos em circulação: a saúde como um direito humano fundamental; as desigualdades como inaceitáveis; a responsabilidade do governo sobre a saúde dos cidadãos; e a participação nas decisões do campo da saúde como um direito da população (Buss, 200o). Podemos observar uma continuidade desse discurso, em 1986, na I Conferência Internacional sobre Promoção da Saúde, em Ottawa (Canadá), que promulgou a ideia de saúde como sinônimo de qualidade de vida e, portanto, resultante de fatores como alimentação, justiça social, ecossistema, renda, educação, entre outros (Czeresnia, 2003).
A promoção da saúde, conforme Carvalho (2004), emergiu por conta da crise da biomedicina, que implicou uma resposta sanitária aos desafios impostos, tanto estrutural (não se poderia oferecer uma medicina especializada para toda a população) como pelos limites de sua eficácia terapêutica. Nesse sentido, seguindo Czeresnia (2003, p. 43), podemos refletir sobre o "limite dos conceitos de saúde e de doença referentes à experiência concreta da saúde e do adoecer”. Ainda segundo a autora, para buscar a consciência desse limite é preciso modificar radicalmente nossos discursos e práticas por meio da consideração dos limites da construção científica e do seu "inevitável caráter redutor", ao reconhecermos que nenhum conceito ou sistema de conceitos poderia dar conta das singularidades, pois “o conceito expressa identidades, já a unidade singular é expressão da diferença" (Czeresnia, 2003, p. 45).

De acordo com Furtado e Szapiro (2012), os conceitos acerca da promoção da saúde se integram em dois grandes grupos: no primeiro, eles se relacionam ao âmbito coletivo e às influências do ambiente e dos determinantes sociais no processo saúde-doença. Nesse grupo encontramos as políticas públicas saudáveis e o empoderamento (empowerment) dos saberes das comunidades. No segundo grupo estão as questões relacionadas aos estilos de vida e à adequação a hábitos considerados saudáveis, com ações que promovem a educação para o enfrentamento dos riscos relativos aos comportamentos individuais.

Para Carvalho (2004), também haveria dois grupos conceituais acerca da promoção da saúde: o primeiro seria mais inclinado para uma atualização dos compromissos com o bem comum - equidade, democracia, cidadania, participação, entre outros -, e o segundo considera os discursos da promoção da saúde fortalecedores do modelo neoliberal, que vincula a saúde a uma ideia de autocuidado, assim como produz discursos de verdade acerca de quais comportamentos e condutas os indivíduos devem seguir e quais devem evitar para viver com saúde.

Castiel (2010) considera que a promoção da saúde desloca a ênfase da medicalização, cuja abordagem comportamentalista advoga por adaptações aos estilos de vida, conforme as direções apontadas 
pelos fatores de risco. As práticas de prevenção de riscos visam produzir um indivíduo que é o autor de sua própria saúde, com objetivo de prolongar a vida. Nesse sentido, ainda segundo Castiel (2010), vivemos sob um epidemiopoder, termo cunhado pelo autor ao apontar uma normatividade de base epidemiológica que orienta, por meio de discursos de promoção da saúde, os comportamentos saudáveis que podem prevenir doenças. Isso significa saber conduzir a própria vida de modo ponderado, seguindo informações baseadas em evidências científicas, para aderir a um estilo de vida consideradosaudável.

Produzir estatísticas sobre os riscos, segundo Rocha (2005), é um modo de subjetivar e governar a vida, pois regula as condutas em função do medo de ficar ou estar exposto aos perigos que tais cálculos nos informam. Nesse sentido, o risco torna-se um dispositivo de controle da sociedade e uma importante estratégia biopolítica ao produzir discursos de verdade baseados em critérios científicos que conferem valores morais sobre os modos de levar a vida. Os dispositivos de disciplina e normalização - como a escola, a família, a fábrica, o hospital, entre outros - são modelos cujo apogeu se localizou no início do século XX e que caracterizavam a sociedade disciplinar. De acordo com Deleuze (1992), após a Segunda Guerra Mundial, tais dispositivos entraram em crise em favor das novas forças que lentamente se instalaram e criaram novos arranjos nas relações de poder, os quais configuram a sociedade de controle.

Essa transformação, segundo Rocha (2009, p. 588), ocorre sob uma mudança na lógica do exercício dos poderes, de tal forma que "a violência física (que visa a controlar os corpos e às ações através do suplício, da marca, da força física) ainda existe, embora menos frequente e mais reprovável", e os mecanismos da sociedade disciplinar apoiados no poder-saber continuam atuando sobre os corpos e as subjetividades, embora menos acreditados. Nessa conjuntura, podemos perceber que "o controle se instrumentalizou com variadas tecnologias. Mudou (está mudando), sobremaneira, o modo como nos fazemos sujeitos" (Rocha, 2009, p. 588), posto que na atual sociedade de controle somos agenciados e modulados através de valores, desejos, verdades e práticas.
No contexto das sociedades de controle, segundo Pelbart (2015), a vida foi tomada de assalto por mecanismos que modulam a existência, e não é necessária a vigilância panóptica, pois nós mesmos nos vigiamos ao seguirmos os preceitos científicos, adequando nossos corpos às normas científicas da saúde, as quais nos informam que devemos ser longevos, equilibrados, moderados, ativos, felizes, entre outras prescrições que visam modular nossas condutas. Nesse sentido, Pelbart (2015, p. 20) afirma que

o poder penetrou em todas as esferas da existência e as mobilizou e as pôs para trabalhar em proveito próprio. Desde os genes, o corpo, a afetividade, o psiquismo até a inteligência, a imaginação, a criatividade, tudo isso foi violado e invadido, mobilizado e colonizado, quando não diretamente expropriado pelos poderes.

Assim, na sociedade de controle, devemos gerenciar nossas condutas e, como empresários de si, cabe-nos procurar ficar bem informados sobre os riscos a se evitar para conseguirmos nos manter com saúde, tarefa que inclui almejar muitas metas e seguir várias prescrições para dar conta da ampliação dos fatores que podem constituir modos de vida considerados saudáveis. São nesses regimes de verdade, relacionados aos estilos de vida referidos pela promoção da saúde, que as Pics se encontram incluídas. Elas não deixaram de ser disciplinadas, normatizadas e regulamentadas pelas regras da razão moderna ocidental, mas parece que, atualmente, o que mais importa é promover um discurso sanitário em que se estabeleça a responsabilidade de cada indivíduo na administração de seus próprios riscos (Furtado; Szapiro, 2012).

Nesse contexto, parece que os regimes de verdade da promoção da saúde sobre autonomia e responsabilidade individual no cuidado impregnam nossas subjetividades com modelos de vida e discursos sobre como devemos viver, fundamentados nas verdades produzidas pelas evidências científicas, que tomamos como definitivas realidades, naturais e seguras para nos guiar nas escolhas que fazemos ao longo da vida.

Ao aplicar a todas as dimensões da vida uma valoração plasmada à ideia de saúde como um 
mecanismo de captura das singularidades, que não são mais tão facilmente disciplinadas, as Pics parecem configurar tecnologias indispensáveis para a composição do campo da saúde. Primeiro, pelo discurso do autocuidado bem estabelecido nessas modalidades que, ao legitimar a liberdade de cada um para escolher práticas de saúde não biomédicas, procura desresponsabilizar o Estado em relação à garantia de direitos sociais, como de um sistema de saúde público e universal de qualidade; e, segundo, pela variedade de saberes e práticas que constituem as Pics, conferindo a esse objeto o poder de produzir identidades travestidas de ilimitados desejos. Afinal, as 29 modalidades de Pics se prestam para cumprir diversos discursos de verdade. Ainda que convergentes com o cuidado e a gerência de cada um sobre sua própria saúde, há, nesse objeto, modos muito variados de atuar sobre o próprio corpo.

\section{Considerações finais}

Como o corpo é um objeto de investimento político, os biopoderes visam modular e controlar as experiências que não estão ainda governadas, que podem produzir corpos e subjetividades não sujeitadas aos poderes hegemônicos. Esses corpos e subjetividades desviantes podem ser capturados em sua variedade e adequados a narrativas padronizadas, justamente por meio da variedade de possíveis experiências que derivam das Pics. Em seguida, essa variedade, ao mesmo tempo que vai sendo trabalhada pelos discursos de verdade biomédicos, em busca de uma homogeneização, normatização e disciplinamento dos saberes e das práticas não convencionais de saúde, também produz a circulação e subjetivação dos discursos dos regimes de verdade da promoção da saúde, na vertente que incentiva o autocuidado e responsabiliza o sujeito pela gestão dos riscos e pela adesão a estilos de vida saudáveis. Assim, as Pics apresentam uma versatilidade muito útil para atrair os mais diferentes desejos. Nesse sentido, as Pics podem funcionar como ferramentas que viabilizam o governo das condutas, tanto nos moldes das sociedades disciplinares como nos moldes da sociedade de controle. Essa versatilidade das Pics num momento de transição de modelos de sociedades e mecanismos de poder, ao que tudo indica, será bastante explorada nos próximos tempos no campo da saúde para dar conta do projeto neoliberal de sociedade.

Pensamos que os regimes de verdade que constituem as Pics nas políticas públicas de saúde configuram mecanismos que, tal como os discursos e as práticas de promoção da saúde, procuram regular e moldar os corpos e as subjetividades. Dessa forma, operam uma biopolítica contemporânea que se vale da produção de verdades que, legitimadas pelas evidências científicas, se estabelecem como modos de viver imprescindíveis para a manutenção dos poderes hegemônicos. Assim, na impossibilidade de manter os corpos e as subjetividades enquadrados em comportamentos disciplinados, normalizados e regulados, abrem-se as cortinas do teatro da liberdade, e entram em cena as táticas de excitação da liberdade, esse dispositivo que ardilosamente se adianta às resistências para governá-las, retirando-lhes potência e modulando seus fluxos para uma capitalização utilitária dos desejos. Portanto, em nossa atualidade, não se trata apenas de perder direitos sociais, como a saúde universal e gratuita: trata-se, também, de ter nossas vidas controladas e utilizadas para o consumo.

\section{Referências}

BAPTISTA, T. W. F.; MATTOS, R. A. Sobre política (ou o que achamos pertinente refletir para analisar políticas). In: MATTOS, R. A.; BAPTISTA, T. W. F. (Org.). Caminhos para análise das políticas de saúde. Porto Alegre: Rede Unida, 2015. p. 83-149.

BRASIL. Ministério da Saúde. Portaria nº 971, de 3 de maio de 2006. Aprova a Política Nacional de Práticas Integrativas e Complementares (PNPIC) no Sistema Único de Saúde. Diário Oficial da União, Brasília, DF, 4 maio 2006a. Seção 1, p. 20. Disponível em: <https://bit.ly/35vJsGg>. Acesso em: 25 nov. 2019.

BRASIL. Ministério da Saúde. Secretaria de Atenção à Saúde. Departamento de Atenção Básica. Política Nacional de Práticas Integrativas e Complementares no SUS: atitude de ampliação de acesso. Brasília, DF, 20o6b. Disponível em: <https://bit.ly/2OdaAUP>. Acesso em: 4 set. 2018.

BRASIL. Ministério da Saúde. Departamento de Atenção Básica. Portaria no 702, de 21 de março 
de 2018. Altera a Portaria de Consolidação n ${ }^{0} 2 /$ GM/MS, de 28 de setembro de 2017, para incluir novas práticas na Política Nacional de Práticas Integrativas e Complementares - PNPIC. Diário Oficial da União, Brasília, DF, 22 mar. 2018. Seção 1, p. 74. Disponível em: <https://bit.ly/2D8NXud>. Acesso em: 4 set. 2018.

BUSS, P. M. Promoção da saúde e qualidade de vida. Ciência \& Saúde Coletiva, Rio de Janeiro, v. 5, n. 1, p. 163-177, 2000.

CAPONI, S. Viver e deixar morrer: biopolítica, risco e gestão das desigualdades. Revista Redbioética/Unesco, Montevidéu, ano 5, v. 2, n. 10, p. 27-37, 2014 .

CARVALHO, S. R. As contradições da promoção à saúde em relação à produção de sujeitos e a mudança social. Ciência \& Saúde Coletiva, Rio de Janeiro, v. 9, n. 3, p. 669-678, 2004.

CASTIEL, L. D. Risco e hiperprevenção: o epidemiopoder e a promoção da saúde como prática biopolítica com formato religioso. In: NOGUEIRA, R. P. (Org.). Determinação social da saúde e reforma sanitária. Rio de Janeiro: Cebes, 2010. p. 161-179.

COSTA, A. M. Integralidade na atenção e no cuidado a saúde. Saúde e Sociedade, São Paulo, v. 13, n. 3, p. 5-15, 2004.

CZERESNIA, D. O conceito de saúde e a diferença entre prevenção e promoção. In: CZERESNIA, D.; FREITAS C. M. (Org.). Promoção da saúde: conceitos, reflexões, tendências. Rio de Janeiro: Editora Fiocruz, 2003. p. 43-57.

DELEUZE, G. Post-scriptum sobre as sociedades de controle. In: DELEUZE, G. Conversações. Rio de Janeiro: Editora 34, 1992. p. 219-226.

FOUCAULT, M. Microfísica do poder. 22. ed. São Paulo: Graal, 2006.

FOUCAULT, M. A verdade e as formas jurídicas. Rio de Janeiro: Nau, 2013.

FURTADO, M. A.; SZAPIRO, A. Promoção da saúde e seu alcance biopolítico: o discurso sanitário da sociedade contemporânea. Saúde e Sociedade, São Paulo, v. 21, n. 4, p. 811-821, 2012.
GAUDENZI, P.; ORTEGA, F. O estatuto da medicalização e as interpretações de Ivan Illich e Michel Foucault como ferramentas conceituais para o estudo da desmedicalização. Interface: Comunicação, Saúde, Educação, Botucatu, v. 16, n. 40, p. 21-34, 2012.

LIMA, K. M. S. V.; SILVA, K. L.; TESSER, C.

D. Práticas integrativas e complementares e relação com promoção de saúde: experiência de um serviço municipal de saúde. Interface: Comunicação, Saúde, Educação, Botucatu, v. 18, n. 49, p. 261-272, 2014.

LUZ, M. T. Estudo comparativo de racionalidades médicas: medicina ocidental contemporânea, homeopática, chinesa e ayurvédica. In: LUZ, M. T.; BARROS, N. F. (Org.). Racionalidades médicas e práticas integrativas em saúde. Rio de Janeiro: UERJ, 2012. p. 25-48.

MARTINS, P. H. As outras medicinas e o paradigma energético. In: LUZ M. T.; BARROS, N. F. (Org.). Racionalidades médicas e práticas integrativas em saúde. Rio de Janeiro: UERJ, 2012. p. 309-342.

MERHY, E. E.; FEUERWERKER, L. C. M. Novo olhar sobre as tecnologias de saúde: uma necessidade contemporânea. In: MANDARINO, A. C. S.; GOMBERG, E. (Org.). Leituras de novas tecnologias e saúde. Salvador: Edufba; São Cristóvão: Editora UFS, 2009. p. 29-56.

MOEBUS, R. L. N.; MERHY, E. E. Genealogia da Política Nacional de Práticas Integrativas e Complementares. Saúde em Redes, Porto Alegre, v. 3, n. 2, p. 145-152, 2017.

OMS - ORGANIZACIÓN MUNDIAL DE LA SALUD. Estrategia de la OMS sobre medicina tradicional 2002-2005. Genebra, 2002. Disponível em: <https://bit.ly/2Oe46EU>. Acesso em: 4 set. 2018. OMS - ORGANIZACIÓN MUNDIAL DE LA SALUD. Estrategia de la OMS sobre medicina tradicional 2014-2023. Genebra, 2013. Disponível em: <https:// bit.ly/2KMgHNy>. Acesso em: 4 set. 2018.

PELBART, P. P. Políticas da vida, produção do comum e a vida em jogo... Saúde e Sociedade, São Paulo, v. 24, p. 19-26, 2015. Suplemento 1. 
PERURENA, F. C. V. Institucionalização de práticas integrativas e complementares no Sistema Único de Saúde!? História, Ciências, Saúde: Manguinhos, Rio de Janeiro, v. 21, n. 1, p. 361-363, 2014.

PINHEIRO, R. Integralidade em saúde. In: ESCOLA POLITÉCNICA DE SAÚDE JOAQUIM VENÂNCIO; ESTAÇÃO DE TRABALHO OBSERVATÓRIO DE TÉCNICOS EM SAÚDE. Dicionário da educação profissional em saúde. Rio de Janeiro: Fiocruz, 2006. p. 159-166.

QUEIROZ, M. S. O sentido do conceito de medicina alternativa e movimento vitalista: uma perspectiva teórica introdutória. In: NASCIMENTO, M. C. (Org.). As duas faces da montanha: estudos sobre medicina chinesa e acupuntura. São Paulo: Hucitec, 2006. p. 19-39.

RAGO, M. Dizer sim à existência. In: RAGO, M.; VEIGA-NETO, A. Para uma vida não fascista. Belo Horizonte: Autêntica, 2015. p. 253-267.
ROCHA, C. M. F. A escola na mídia: nada fora do controle. 2005. Tese (Doutorado em Educação) Universidade Federal do Rio Grade do Sul, Porto Alegre, 2005.

ROCHA, C. M. F. As tecnologias, as subjetividades contemporâneas e o (hiper)controle. Revista MalEstar e Subjetividade, Fortaleza, v. 9, n. 2, p. 575601, 2009.

SCHVEITZER, M. C.; ZOBOLI, E. L. C. P. Papel das práticas complementares na compreensão dos profissionais da atenção básica: uma revisão sistemática. Revista da Escola de Enfermagem da USP, São Paulo, v. 48, p. 189-196, 2014. Número especial.

ZORZANELLI, R. T.; ORTEGA, F.; BEZERRA JÚNIOR, B. Um panorama sobre as variações em torno do conceito de medicalização entre 19502010. Ciência \& Saúde Coletiva, Rio de Janeiro, v. 19, n. 6, p. 1859-1868, 2014.

\section{Contribuição dos autores}

As autoras participaram igualmente de todas as etapas de elaboração do artigo.

Recebido: 20/06/2019

Aprovado: 29/10/2019 